\title{
11
}

\section{THE COMMERCIALISATION OF LINGUISTIC EXPERTISE IN THE ASYLUM VETTING PROCESS}

\author{
Enam Al-Wer and Maria Fanis
}

The process of asylum seeking is an exemplar case of globalisation in that illegal migration and asylum seeking have become a global phenomenon. The asylumseeking application process is embedded in the current globalisation practices because it comprises a flow of migrant populations across state borders. As such, it interacts with the flows of commercial and financial activities, information and ideas. In the case of asylum seekers, we have the flows of undocumented immigrants and the flows of knowledge and information, the latter coming from a variety of groups of experts, professionals, and state agents who are situated in more than one location. In those situations, the state willingly participates in and promotes the free market spirit of current day globalisation. It does so by shedding parts of its services to the commercial sector. The incentive behind this commercialisation of state services rests on the logic of efficiency, cost-cutting, and streamlining, which characterise current-day globalisation. The linguistic vetting of asylum seekers is an example of services that states have turned to the commercial sector. Therefore, we argue that the linguistic analysis can best be analysed critically through the lens of globalisation. We show how the state's choice to commercialise the linguistic services needed in the vetting process creates a situation where the expert linguists find themselves working at cross-purposes as they are assigned linguistic analyses that often invalidate each other, rather than enable cross-fertilisation of expertise among the linguists involved.

The asylum-seeking application process and its adjudication rest on a global infrastructure of services, whereby a variety of specialists, experts, private businesses, and state agencies all participate in the determination of the merits of each case. It is precisely the state's willing participation in globalisation that undermines the use of expert knowledge in asylum seeking. Specifically, it is the engagement of the state as well as the private entities that jeopardises the use of expert knowledge. We analyse the use of language in asylum seeking as part of this interlocking of the local 
and the global, state and private interests, and the effects of these interlocked flows on the use of expert knowledge.

It is often the case that immigrants landing on the frontier of Western states lack either appropriate documentation or any documentation at all, which is resolved through a vetting process. The vetting mechanism of asylum seeking is not discussed as often as the more general phenomenon of immigration itself. Even less discussed is the appeal process of asylum vetting, which is the focus of the current chapter, and in particular the way] it is practiced in the United Kingdom. We believe that when we embed the asylum vetting process within the larger processes of globalisation, we can ascertain the political results at the interface of the nation state and the immigrant population. We posit that the privatisation of the asylum-seeking services contorts rather than facilitates the actualisation of the universal rights of the immigrants.

The state has certainly acknowledged publicly the necessity of commercialising state-owned services in the name of, inter alia, economic efficiency, entrepreneurism, better allocation of services, competitive pricing and high quality of services, higher transparency and accountability, and freedom of choice for consumers. The commercialisation of the linguistic services examined in this chapter fulfils more than one of these incentives. It may also be the case, although not acknowledged by states, that the commercialisation of these services is motivated by the desire, on the part of the state, to curb the influx of undocumented immigrants (see Guiraudon \& Lahav 2000; Messina 1996; Guiraudon 2001). Irrespective of the motivation, what we witness in the case study presented in this chapter is that the commercialisation of these linguistic services confounds, and perhaps to a certain extent also delegitimises, the notion of applying the right of asylum to the deserving among the undocumented refugees.

The practice of resorting to linguistic evidence has expanded since the 1990s to include countries in Europe, North America and the Southern Hemisphere, and so has the commercialisation of the use of linguistic analysis for this purpose. ${ }^{1}$ The parties engaged in this practice include border agencies (government-run bodies) as well as private companies who market and sell their businesses transnationally. ${ }^{2}$ We question the assumption that authoritative or scientific knowledge can be used effectively once agencies become private by using the concept of "epistemic communities" as an analytical framework. In particular, we examine whether the commercialisation of the linguistic vetting services allows the community of scientists to come together in the pursuit of the public good. As will be argued, the commercialisation of the linguistic vetting services can lead to a situation where linguists are dispersed in different spaces and tasked with types of analyses which are often noncomplementary. This line of inquiry is part of a larger discussion on the role of expert knowledge in language analysis for asylum seeking. For example, Campbell (2012) questions the scientific basis and neutrality of language analysis as conducted by the British Home Office. Blommaert (2009) argues that dialects do not map easily onto the existing national borders, something that the established language analyses miss. ${ }^{3}$ Our approach is different in that we link the role of expert 
knowledge to the state-private partnerships that have become all too common under globalisation. The framework of epistemic communities serves as a benchmark for evaluating what expert knowledge was able to accomplish in the past and what it can achieve now. While this is the main goal of the chapter, we also want to sketch out some preliminary thoughts regarding the possibility of expertise remaining relevant in global and national politics.

In the next section, we introduce the concept of epistemic communities and explain how it can be used to assess the role that expert knowledge plays in the process of asylum seeking.

\section{Epistemic communities}

Peter Haas, who coined the phrase "epistemic communities", defined it as "a network of professionals with recognized expertise and competence in a particular domain and an authoritative claim to policy-relevant knowledge within that domain or issue-area" (Haas 1988: 3). Some of the best-known examples of epistemic communities in action date to the period of the Cold War, when epistemic communities were very influential in pushing the United States and the Soviet Union towards arms controls. They have also been instrumental in putting together the Mediterranean Action Plan, as well as several other environmental policies. We argue that the linguistic experts that are called upon to render their scientific knowledge during the asylum-seeking process are members of such an epistemic community. While the linguists involved in adjudicating the petition for asylum do not coordinate with each other in a manner that would resemble a network of experts, they still are members of a scientific community whose knowledge production is both recognised and sought by the community and governments. In the same way that, for example, physicists or other scientists in academia are considered the experts in their respective fields of research, linguists are the experts on all matters regarding language and language use. In other words, the linguists in the process described here are members of a group of professionals who are recognised for their "expertise and competence" in the analysis of languages. Moreover, in accordance with other characteristics of an epistemic community, the study and analysis of languages constitutes a "particular domain" of knowledge and specialised research. Equally, linguists are often invited to provide "authoritative" opinions based on their ability to do linguistic analysis that produces knowledge which is relevant for policymaking, and, in the case at hand, for vetting asylum petitioners.

Furthermore, sociolinguists constitute an epistemic community according to the four substantive criteria laid out by Haas: (1) sociolinguists share important principled beliefs, which stipulate that all aspects of social life, such as cultural norms and expectations, as well as social context, affect the "way language is used", and that society at large influences language (Gumperz \& Cook-Gumperz 2008). As a result, sociolinguists are expertly situated to assess the normative values that guide the "social action of community members" (Haas 1988: 5) as these pertain to language use, which is the issue at hand in the process of asylum vetting. (2) Sociolinguists 
have developed shared causal beliefs about the use of language based on their analysis of language practices of members of the community. One such fundamental causal mechanism is that language varieties differ along metrics of social stratification based on ethnicity, religion, gender, education, age and other similar factors. Also, these different language varieties are social markers used by people to categorise others in different socioeconomic classes. Another such shared belief with causal implications is that there are "language universals", which are concerned with the "learnability of all languages", and that there are rules and principles that guide speakers in how to construct and interpret sentences (Wardhaugh \& Fuller 2015). (3) Sociolinguists devise their fieldwork based on the shared notion of validity according to which the selection of number and type of participants is to be based on what the fieldwork is expected to measure. Also, sociolinguistic research is governed by shared notions of reliability which dictate whether, and if so when, an item is consistently measured (Wolfram 2011: 300). (4) Sociolinguists use common practices, for example the observations regarding the speech community (Coupland 2009; Patrick 2004) and social network (Milroy 1980) when ascertaining the societal effect on the use of language in their belief that knowledge production will benefit human welfare. All of these characteristics apply to the linguists engaged in the asylum vetting process. So, to what extent do the epistemic communities of linguistic experts in this case assist the state in the vetting of the asylum seeker petitioner? In order to discuss this question, we first explain briefly how linguists are engaged in vetting asylum cases.

\section{The process of linguistic analysis for the determination of origin (LADO)}

One procedure that has been followed in several countries around the world since the 1990s is that of vetting origins of, mostly, undocumented asylum seekers by commissioning a linguistic analysis of the applicant's speech. The analysis is usually based on empirical data obtained through an interview in the language of the asylum seeker. The purpose of the interview is twofold: to obtain a sample of the applicant's speech, which is akin to the procedures followed in sociolinguistic research, and to vet the applicant's general knowledge of the locality in which they were socialised. The length, quality and content of the interview varies across agencies. For instance, in the practice of Lingua, a language analysis unit run by the Swiss State Secretariat for Migration, the interview lasts approximately one hour, and covers a range of topics pertaining to the applicant's life and experiences (siblings, schooling, profession), their familiarity with landmark locations in the alleged place of origin (schools, neighbourhoods, shops, places of worship), and its politics, culture and social practices. In the practice of other agencies, however, the interview can last a mere fifteen minutes and cover much more restricted ground, as testified by one of the authors of this chapter who has extensive experience as a practitioner in the field. 
The recorded interview is then analysed by a linguist who is normally an expert in the dialects of the region or country that the applicant alleges to be their origin. This expert linguist (henceforth Expert 1) is asked to write a linguistic report and to assess, on the basis of the analysis of the recorded interview, how likely it is that the applicant was socialised in the country they claim as their origin. The linguistic analysis may be commissioned directly through a state agency or through a private entity franchised by the state.

The length and quality of the linguistic report varies from agency to agency. For instance, in the reports commissioned by Lingua, the expert analyst is expected to provide analysis at five linguistic levels where possible: phonetics, phonology, morphology, syntax and lexicon; and to provide a summary and conclusion to each section, in addition to a final general conclusion. These requirements are informed by fundamental sociolinguistic principles of how dialects vary. On the other hand, some linguistic reports, particularly those commissioned by some private firms that specialise in linguistic analysis for the purpose of determining origins of asylum seekers, are much less detailed and less rigorous.

The linguistic report is usually used by the border agencies as part of the evidence for the vetting of the application. In cases where the decision rendered by the authorities is not appealed by the applicant, no further involvement of linguists is usually required. On the other hand, if an appeal process is activated, in the United Kingdom private lawyers become involved, and the expenses are covered by legal aid. At this stage, two types of linguists can be engaged by lawyers acting on behalf of the appellant: a dialect expert (henceforth, Expert 2) who is asked to conduct an analysis of the original interview with the applicant (if the recording is available) or to conduct a new interview and write a contra analysis on this basis; and a general linguistic expert (e.g., a general sociolinguist/linguist, henceforth Expert 3), who is commissioned to perform a different task, namely to critique the original linguistic analysis that was commissioned by the authorities at the first stage of the vetting process. ${ }^{4}$ It is important to note that Expert 3, the general sociolinguist/ linguist, does not necessarily speak or know the language/dialect of the applicant, and therefore the critique they produce is based solely on general disciplinary criteria, and does not address the accuracy of the original analysis as it pertains to the dialect in question. In other words, while the dialect expert (Expert 2) can and does provide analysis that is idiolect-, dialect- and community-specific on the basis of the empirical evidence supplied, the general linguistic expert (Expert 3) undertakes an analysis of the analysis supplied by Expert 1, that is, a type of meta-analysis. Expert 3, therefore is not expected (or indeed qualified) to determine whether the conclusions of the original analysis are correct (see further later in this chapter).

We argue that the employment of private actors, which might happen at the initial stage but certainly occurs at the appeal stage (if one is triggered), undermines the benefit that the larger society and governmental policy can derive from this epistemic community of linguists. In view of the distinct roles and competencies of the two experts engaged at the appeal stage, there is a high probability of these linguists working against each other rather than pooling their expertise to establish 
the facts of the case. In order to substantiate our argument, in the next section we present an actual case of an applicant's appeal.

\section{Case study}

The case we discuss in this section is an appeal case from the United Kingdom. ${ }^{5}$ The initial analysis by Expert 1 was provided by a private firm on behalf of the border agency. This analysis rejected the applicant's claim of a Syrian origin with a "very high" degree of certainty, and concluded instead that the applicant's speech was Egyptian. The applicant appealed this conclusion. The lawyers acting on behalf of the applicant first engaged an expert in the dialects of the region (Expert 2) to provide reanalysis of the original sample of speech, which was obtained through a recorded interview with the applicant. After receiving the report of Expert 2, which was detrimental to their client's case, the lawyers subsequently engaged a general linguist (Expert 3) for the same case, whose expertise is in sociolinguistics but who did not know Arabic (the native language of the applicant). Expert 3 was asked to critique the analysis performed by Expert 1 . We begin with a summary of the report supplied by Expert 3 .

\section{Expert 3}

The general sociolinguist, Expert 3, concluded that the analysis conducted by Expert 1 was unsafe on several valid scientific points. The report by Expert 3 consists of 29 pages, divided into seven sections. Each section provides a detailed and clear exegesis of the standards of practice endorsed by the scientific (linguistic) community. Expert 3 takes great care in addressing all of the questions of the task assigned by the lawyers on behalf of the applicant. The report goes to great lengths in explaining how sociolinguistic theories and principles apply to the case at hand. Moreover, it specifies the standards of practice endorsed by the scientific community as they apply to the report produced by Expert 1. Furthermore, the report by Expert 3 contains a section on legally recognised standards in forensic linguistic practice. The report also deals with the institutional pressures of time and cost, and suggests that they should be taken into consideration when evaluating linguistic reports. Finally, in this detailed report, Expert 3 encourages administrators, tribunals and judges to recognise that linguistic analysis is not infallible. Overall, the report written by Expert 3 is an exemplar of the use of expert knowledge in critiquing the report written by Expert 1; the latter contained a linguistic analysis of the applicant's dialect, assessing the validity of the applicant's claim of origin (see later in this chapter).

Insofar as the linguistic analysis of the original report is concerned, the report by Expert 3 comments on the following issues:

- the low number of examples cited to demonstrate the point made by Expert 1 , pointing out that one example is not enough to warrant the conclusion reached 
- lack of consideration of well-researched and well-documented universal tendencies of alternations between sounds; in this particular case, the alternation between the sounds [3] and [g] found in many languages

- failure of the report to mention the linguistic constraints on the variation found in the speech of the applicant; in particular, Expert 3 comments on the failure by Expert 1 to provide details about the linguistic conditions under which the dialect in question retains consonant clusters

- lack of specification, in some parts, of the exact linguistic features referred to in the report by Expert 1. Expert 1 cites lexical items without commenting on the specific linguistic feature these items are supposed to demonstrate.

Expert 3 concluded that the analysis provided by Expert 1 should not be accepted as scientific evidence, or at least it should be treated with severe scepticism.

Notably, the points that Expert 3 raises, while valid scientifically, cannot address the issue that triggered the appeal process in the first place, namely the rejection of the applicant's claim about country of origin/place of socialisation on the basis of the mismatch, stipulated by Expert 1, between the applicant's idiolect and their alleged place of origin. To do that, a second analysis of the applicant's speech by a second dialect expert would have been needed. Instead, what we have here is a metaanalysis of the scientific merits of the analysis conducted by Expert 1, which does not address the central question: is the applicant's linguistic behaviour consistent with their alleged place of socialisation? It is the eperemistemic community of linguists, acting as a pressure group, who advanced the knowledge that linguistic evidence can be used as forensic evidence. But what we see happening here is precisely what happens with meta-analysis, namely that the linguistic forensic evidence is sidelined (in the report by Expert 3), since Expert 3 is not asked to, and cannot, comment on the applicant's dialect per se, but on the scientific merit of the original analysis.

\section{Expert 2}

Similar to Expert 3, Expert 2 finds serious and alarming concerns with the poor linguistic analysis of Expert 1. Overall, Expert 2 finds the analysis by Expert 1 to be unprofessional. According to Expert 2, although the linguistic features selected by Expert 1 include some of the most salient features to distinguish between the dialects involved (Egyptian and Syrian), the analysis fails to adhere to the scientific standards of the description of these features, and fails to capture the structural rules of the dialects in question at all linguistic levels, for example, rules concerning vowel length, stress placement, vowel height, syllable structure, assimilation, and WH-in situ. Although Expert 2 finds all of these scientific failures in the report by Expert 1, the reanalysis undertaken by Expert 2 of the same speech sample concurs with the conclusion by Expert 1, namely to reject the applicant's claim of Syrian origin, confirming, further, the likelihood that the place of socialisation of the applicant was Egypt. It is important to point out in this context that the lawyers are not obliged to reveal this conclusion before the court; instead, they can 
simply ignore Expert 2's report and only cite the methodological criticisms, that is, the report by Expert 3. Although the report by Expert 3 makes valid and detailed criticisms of the original analysis, it does not in itself enable the court to arrive at a decision regarding the appellant's origin on the basis of linguistic evidence, particularly if (as in this case) the appellant's lawyers chose not to make the report by Expert 2 available to the court.

\section{Discussion}

An important implication of the case study presented above is that, intentionally or unintentionally, the commercialisation of the linguistic analysis negates the significance of epistemic communities in the vetting of asylum seekers, and in particular in the case at hand, that of appeal cases. Specifically, the use of the expert community is found to complicate rather than advance the linguistic analysis in determining the applicant's origin in asylum cases. What is important to emphasise is that both Expert 1 and Expert 3 are chosen by private entities, by commercial firms for language analysis in phase 1 (Expert 1), and by private law firms in phase 3 (Expert 3). The faulty report by Expert 1 here points to a recurrent criticism of the way language analysis has been used in vetting immigration and asylum seekers (see Patrick 2010, 2016).

What we see happening then is that the private interest at phase 1 can often lead to the recruitment of less qualified professionals. The commercialisation of the linguistic analysis has also given incentives to some linguists to put themselves proactively forward for such tasks, even if they are not the experts in the field, whereas others, who may be far more qualified, simply have no desire to be involved in LADO. Based on this likely eventuality at phase 1, we can foresee why Expert 3 (the area linguist who conducted a meta-analysis) will most likely provide reasons for a successful appeal, if the case were to be appealed. Looking at our earlier case study, we see that even when the final conclusion by both Expert 1 and Expert 2 is consensual (here, against the applicant's claim of origin), the fact that the report by Expert 1 is scientifically faulty will most certainly lead to a reversal of the recommendation by Experts 1 and 2. This outcome provides a clear picture of how epistemic communities are hampered in putting their scientific knowledge to the good of society when that knowledge is funnelled through commercial means. If, and when, Expert 1 provides a sub-par scientific analysis, which is a concern, Expert 3 will always find it wanting from a scientific point of view. Expert 2, on the other hand, can proceed unencumbered by a faulty report (the report by Expert 1) because they only evaluate the dialect/language.

Our findings point to two structural impediments for the use of linguistic analysis due to the commercialisation of the appeals process, that any good intentions by experts, governments, or private firms to adhere to the LADO criteria cannot overcome. It is quite interesting that even though Expert 2 (the dialect expert) and Expert 3 (the area linguist) found the report by Expert 1 to be seriously faulty, they can still be seen to diverge. This is so because, firstly, these two experts are given two 
different tasks. To the extent that law firms have ascertained that Expert 3's metaanalysis cannot, in most cases, complement expert 2's analysis, but rather offer a counterpoint to it, they are likely to commission scientists who do different kinds of analyses. But perhaps more crucial is the fact that Expert 2 and Expert 3 represent two different levels of linguistic analysis whose epistemologies differ markedly in that they analyse linguistic variables at different levels of aggregation. Expert 3 applies general disciplinary criteria whereas Expert 2 focuses on the microanalysis of the lexical, grammatical and phonological variables of the language in question. To the degree that the law firm understands the incongruence between the reports originating from these different levels of analysis, as is the case between Expert 2 and Expert 3, it is more likely that it will recruit an expert whose disciplinary specialisation differs from that of Expert 2. The law firm has a strong incentive to appoint a specialist who, notwithstanding their exceptional scientific qualifications, is recruited on the basis of advancing the case of their client. This creates a situation where the applicant's lawyers might pit the linguistic experts against one another (if the report by Expert 2 contradicts the applicant's claim of place of origin). In this case, the private sector's own interest is set up to undermine the potential of the epistemic communities to use scientific knowledge for the greater good. While the two expert linguists, Expert 2 and Expert 3, are summoned by the appeal process to act as the verifiers of scientific knowledge, the private firm has an incentive to use scientific knowledge to the benefit of their client. In this scenario, the linguistic analyses are caught up in disciplinary epistemological differences, which distance them from the normative claims and aspirations of the universal human rights of all immigrants to a fair process.

In the scenario laid out earlier, the expert linguists are put in a position of criticising each other; any report by Expert 1 is liable to be found wanting by Expert 3. Scientists, and in this case academic linguists, are trained to criticise the work of their colleagues, so it is highly likely that Expert 3 would be able to find at least some defects in the original report by Expert 1. We argue that cases where an appeal is upheld on the basis of a critical report by Expert 3, even though the conclusions reached by Expert 1 are correct, undermine the principles of fair treatment of asylum seekers as well as confidence in LADO.

So, to what extent do the epistemic communities of linguistic experts assist the state in the proper vetting of the asylum seeker petitioner? We connect this discussion to examples of past epistemic communities in order to answer this question. We cite the example of, perhaps, the most notable epistemic community from the past - nuclear arms control - whose work changed the international politics of nuclear weapons in the late 1950s, a precarious time between the United States and the Soviet Union. ${ }^{6}$ The effects on the foreign policies of both adversaries of, what Adler called, the American national epistemic community, can hardly be exaggerated. This epistemic community introduced the two superpowers to the idea of nuclear arms control, a novel concept to their strategic worldview until then, and turned it into the conceptual basis for their cooperation for the next 30 years. In the absence of any prior experience with nuclear war, by any nation and not only 
the superpowers, this arms-control epistemic community used insights from theories on human rationality, and through the use of abstract models, simulations, and games, created an arms control theory (Adler 1992: 102-107). The expert knowledge produced could not have been more science-based than this; the epistemic community members comprised mathematicians, economists and strategists. Why does this kind of success elude the use of the linguists' expert knowledge in the appeals case described earlier?

To answer this question, we turn to the process of the creation and dissemination of the arms control theory. According to Adler (1992: 111): "The arms control epistemic community was an informal association of scientists and civilian strategists", which was split into two subgroups with opposing views on nuclear weapons. The first was the "analytical middle marginalists", who believed in the futility of disarmament. The second was the "moderate antiwar marginalists", who believed that reducing nuclear weapons would also reduce tensions between the two superpowers. The first group wanted nuclear weapons to stay, while the second group preferred nuclear disarmament and, if not that, limited arms control measures for controlling the nuclear arms race (Adler 1992: 117). Despite their opposing views these two groups "converged into an epistemic community", as Adler says, because they were united in their desire for the greater good which consisted of the "short-term advantages and necessity of arms control and there was scarcely a member of either group who did not concede the validity of the recommendations of the other" (Adler 1992: 111).

These two groups are analogous to Experts 2 and 3 of the linguistic epistemic community who, while divided by their epistemological predispositions, are united, generally speaking, in reaching a consensual decision regarding the country of origin of asylum seekers, which would be serving the greater good of society in terms of applying the existing policy to asylum appeals. However, as we have discussed earlier, Experts 2 and 3 would never have been able to reach a consensual agreement. The interest of the private firm is skewed towards serving their client, something that prohibits any discussion and collaboration between the experts. Contrary to that, the members of the nuclear epistemic community operating within and with state agencies and non-profit groups were able to keep the channels of communication open and, eventually, procure one of the most astonishing foreign policy accomplishments of the Cold War, which was the beginning of nuclear arms control cooperation between the United States and the Soviet Union. As Adler (1992: 111) remarks:

[c]ertainly some of the epistemic community's members did not get along well, and sometimes there were personal, career, and institutional conflicts. Many of the arms controllers, having made original intellectual contributions in their own fields of expertise and in nuclear strategy, guarded their own ideas and interpretations. But their discussions, arguments, and mutual criticisms actually helped them in shaping a consensus over concepts, surmounting interdisciplinary barriers, and creating a common vocabulary. 
We can easily hypothesise that if the new opposing nuclear groups were serving in a state private partnership schema they would have produced two different scientific analyses with unbridgeable conclusions, despite each group having offered their expert knowledge in good conscience and for the greater good of the society. As we see, the difference between the nuclear and the linguistic epistemic communities is that the members of the former enjoyed continuous and sustained exchange of scientific information that led to a consensus, that is, the nuclear arms control regime. The members of the linguistic community lacked the ability to combine their expert knowledge in a way that they could jointly assess the claims of the applicant.

\section{Conclusion}

The aim of this chapter is to ascertain the effect of the commercialisation of the linguistic services used in the vetting of asylum applicants, and in particular in the appeals phase of this procedure as practiced in the United Kingdom. In order to do that, we proceeded in two ways; first, we situated the appeals process within the larger phenomenon of globalisation. This is premised on several facts, chief among them is that privatising state functions and services in order to achieve efficiency and cost saving, as is the case here with the linguistic services, is a direct result of the political economies of globalisation. Secondly, the increased rate of immigration flows, and specifically of undocumented immigrants, is also an aspect of globalisation. This rate has increased exponentially since the 1990s to become one of the most consequential social trends. ${ }^{9}$ It is in this context that we encounter LADO as a practice of asylum vetting.

The linguists who participate in the analysis of asylum applicants' language are experts who apply their disciplinary epistemological and methodological criteria in comparing the language use of the applicant to the language use in the applicant's alleged social milieu. They are invited by the state, the community, and the private sector to provide expert knowledge and authoritative opinions based on their verified ability to do linguistic analysis. These linguists, therefore, are part of the epistemic communities whose role is to offer expert knowledge on matters of global concern that affect societies deeply. Thinking of these linguists as experts allows us to use the expert use of language as a category for analysis in order to see the effects of language in the specific setting of asylum vetting. This social setting, as explained above, is a place within the state where the service of language analysis is privatised in order to vet asylum seekers. The linguists, as representatives of epistemic communities, want to use their expert knowledge for the greater good. However, as we have shown in this chapter, the commercialisation of the use of the expert's knowledge diminishes its capacity to work for the greater good in the way epistemic communities have done in the past.

We analysed a specific case of LADO, which we paralleled with nuclear arms control as a famous example of an epistemic community at work. This case documented the use of linguistic expertise at the two stages of an asylum-seeking 
appeals case in the United Kingdom. We examined the effect of the commercialisation of expert knowledge with a detailed analysis of the different tasks given to these expert linguists, and the sequence in which the expert use of knowledge by the different linguists built on each other. We concluded that the involvement of private firms in the dispensing of expert knowledge for the vetting of the asylum seeker created structural impediments to an advantageous use of the linguists' analyses. We, therefore, are sceptical whether the state-private partnerships, which have become all too common under globalisation, are suitable for advancing one of the normative components of the globalisation of global issues, which is the advancement of people's universal human rights. Even if in our case it is possible that the sole individual might be able to do better because of these structural impediments, this might not be the case for another individual. In any case, the idea of the universal human rights implies that we create proper procedures that can, to the extent possible, safeguard the application of those rights. However, in this case we have witnessed how the procedures that come out of state-private partnerships are not geared towards this policy goal. This points to specific policy recommendations, namely that any substantial corrective action towards an effective usage of linguistic expertise is a political one. This action cannot be replaced solely by attempts to restructure the LADO process. Any future restructuring of LADO needs to be accompanied by the totality of the asylum vetting processes reverting back to the state. Only under these conditions can the asylum vetting process satisfy the principle of fair treatment, itself an important prerequisite for the universal application of human rights.

\section{Acknowledgements}

We are grateful for the generosity and cooperation of the colleagues who provided us with various parts of the documentation of the case discussed in this chapter. We thank Ms Priska Hubbuch for providing us with the details about Lingua procedures. We are extremely grateful to our colleagues Mike Jones, Peter Patrick, Uri Horesh and Crispin Thurlow for their insightful comments.

\section{Notes}

1 Linguistic analysis for the determination of origin (LADO) is practiced, inter alia, in the United Kingdom, Germany, the Netherlands, Switzerland, Canada, Australia and New Zealand (see Patrick 2010, 2012, 2016).

2 In some cases, the governmental body itself has its own language analysis unit - as is the case in Switzerland - which conducts the process of interviewing applicants and analysing their speech. These governmental units are also engaged in marketing linguistic analysis as a business transnationally.

3 Interest in the effects of language analysis on asylum cases has increased since 2000. Subsequently, a brief document, entitled Guidelines for the Use of Language Analysis in Relation to Questions of National Origin in Refugee Cases, was drawn up by a group of 
linguists. See, for instance, Craig (2012), Eades (2005, 2009, 2010), Patrick (2016, 2019), and Corcoran (2004).

4 The procedure at the appeal stage as outlined here applies to the United Kingdom, but it may vary in other countries. For instance, in Switzerland, if the application is rejected, the claimant is first given the 'right to be heard', whereby they have the opportunity to reply to the points of concern raised in the linguistic analysis. Depending on the claimant's responses, the officer in charge of the case may then ask for additional information from the language analysis unit, which may include a second analysis. Claimants, in the final stage, have the right to appeal at the Federal Administrative Court, which decides whether the original linguistic analysis was convincing and corresponds to quality standards. The court itself can order a new analysis by a different expert. This information was supplied by Lingua, the State Secretariat for Migration, Switzerland.

5 The details were made available to the authors by the analysts involved in this case.

6 See, for instance, John Carvel (2001). www.theguardian.com/uk/2001/jan/25/race.world (last accessed 05.02.2019).

\section{References}

Adler, E. (1992). The emergence of cooperation: National epistemic communities and the international evolution of the idea of nuclear arms control. International Organization, 46(1), 101-145.

Blommaert, J. (2009). Language, asylum, and the national order. Current Anthropology, 50(4), 415-441.

Campbell, J. (2012). Language analysis in the United Kingdom's refugee status determination system: Seeing through policy claims about 'expert knowledge'. Ethnic and Racial Studies, 36(4), 670-690.

Carvel, J. (2001). Immigration rise main social trend of 1990s. The Guardian. Available online at www.theguardian.com/uk/2001/jan/25/race.world (last accessed 01.02.2019).

Corcoran, C. (2004). A critical examination of the use of language analysis interviews in asylum proceedings: A case study of a West African seeking asylum in the Netherlands. Speech, Language and the Law, 11(2), 200-221.

Coupland, N. (2009). The authentic speaker and the speech community. In C. Llamas \& D. Watt (eds.), Language and Identities (99-112). Edinburgh: Edinburgh University Press.

Craig, S. (2012). The use of language analysis in asylum decision-making in the UK - A discussion. Journal of Immigration, Asylum and Nationality Law, 26(3), 255-268.

Deckert, S. \& Vickers, C. (2011). An Introduction to Sociolinguistics: Society and Identity. London: Continuum.

Eades, D. (2005). Applied linguistics and language analysis in asylum seeker cases. Applied Linguistics, 26(4), 503-526.

Eades, D. (2009). Testing the claims of asylum seekers:The role of language analysis. Language Assessment Quarterly, 6(1), 30-40.

Eades, D. (2010). Guidelines from linguists for LADO. In: K. Zwaan, P. Muysken \& M.Verrips (eds.), Language and Origin. The Role of Language in European Asylum Procedures: A Linguistic and Legal Survey (35-41). Nijmegen: Wolf Legal Publishers.

Guiraudon, V. (2001). De-nationalizing control: Analyzing state responses to constraints on migration control. In:V. Guiraudon \& C. Joppke (eds.), Controlling a New Migration World (31-64). New York: Routledge.

Guiraudon, V. \& Lahav G. (2000). A reappraisal of the state sovereignty debate: The case of migration control. Comparative Political Studies, 33(2), 163-195. 
Gumperz, J. \& Cook-Gumperz, J. (2008). Studying language, culture, and society: Sociolinguistics or linguistic anthropology? Journal of Sociolinguistics, 12(4), 532-545.

Haas, P. (1988). Epistemic communities and international policy coordination. International Organization, 46(1), 379-396.

Messina, A. (1996). The not-so-silent revolution: Postwar migration to Western Europe. World Politics, 49, 130-154.

Milroy, L. (1980). Language and Social Networks. Oxford: Blackwell.

Patrick, P. (2004). The speech community. In:J.K. Chambers, P. Trudgill \& N. Schilling-Estes (eds.), The Handbook of Language Variation and Change (573-597). Malden, MA: Blackwell.

Patrick, P. (2010). Language variation and LADO (Language Analysis for Determination of Origin). In: K. Zwaan, P. Muysken \& M.Verrips (eds.), Language and Origin. The Role of Language in European Asylum Procedures: A Linguistic and Legal Survey (73-87). Nijmegen: Wolf Legal Publishers.

Patrick, P. (2012). Language analysis for determination of origin: Objective evidence for refugee status determination. In: P. Tiersma \& L. Solan (eds.), The Oxford Handbook of Language and Law (535-546). Oxford: Oxford University Press.

Patrick, P. (2016). The impact of sociolinguistics on refugee status determination. In: R. Lawson \& D. Sayers (eds.), Sociolinguistic Research: Application and Impact (235-256). London: Routledge.

Patrick, P. (2019). Language Analysis for Determination of Origin (LADO) in Arabicdominant settings. In: E. Al-Wer and U. Horesh (eds.), The Routledge Handbook of Arabic Sociolinguistics. Oxford: Routledge.

Sassen, S. (2008). Territory, Authority, Rights: From Medieval to Global Assemblages. Princeton, NJ: Princeton University Press.

Wardhaugh, R. \& Fuller, J. (2015). An Introduction to Sociolinguistics. Oxford:Wiley Blackwell. Wolfram, W. (2011). Fieldwork methods in language variation. In: R. Wodak, B. Johnstone \& P. Kerswill (eds.), The Sage Handbook of Sociolinguistics (296-312). London: Sage. 